\title{
Several Immunological Parameters in Rabbit Kittens Born to S. japonicum-Infected Mothers
}

\author{
Abdel-Moneim Salim, Alaa Bassioni Ismael \\ Faculty of Applied Medical Science, Department of Medical Microbiology, Taif University, Turaba Branch, Taif, \\ Saudi Arabia \\ Email: salimabdelmoneim55@msn.com
}

Received 7 April 2014; revised 7 May 2014; accepted 10 June 2014

Copyright (C 2014 by author and Scientific Research Publishing Inc. This work is licensed under the Creative Commons Attribution International License (CC BY). http://creativecommons.org/licenses/by/4.0/ c) (i) Open Access

\section{Abstract}

In this study we explored the rabbit as an animal model for the congenital infection of schistosomiasis japonica and assessed the effect of a congenital $S$. japonicum infection on the resistance of rabbit kittens to a postnatal challenge infection. Kittens were challenged 17 - 19 weeks after the primary infection of their mothers. Perfusion was undertaken six weeks after the challenge. At this time parasitological, pathological and immunological parameters, worm reduction rate, granuloma size reduction rate, egg reduction rate, IgG and IgM responses were assessed and compared to that of kittens born to un-infected mothers. The overall prevalence of congenital infection in kittens of infected mothers was $20 \%(12 / 60)$. After a postnatal challenge infection, prenatally infected kittens had a $54.66 \%$ worm reduction rate, $41.45 \%$ egg reduction rate, and $51.76 \%$ granuloma size reduction rate compared to naive kittens. Congenital infection decreases the IgM responses by $39.47 \%$ while it increases the IgG responses by $56.22 \%$. Together, these results indicate that congenital infection induce long-term effects on pathology and immune response patterns in rabbits' subsequently challenge with $S$. japonicum cercariae.

\section{Keywords}

Congenital Infection, Rabbits, S. japonicum

\section{Introduction}

Schistosomiasis japonica, the causative organism for schistosomiasis, is solely prevalent in Southeast Asia where an estimated two million people are infected and 69 - 75 million individuals are at risk of infection. It is 
unique among the major schistosomes infecting humans, as zoonotic transmission is important, with domesticated and wild animals serving as reservoir hosts of the parasite, and an amphibious snail as intermediate host. Although human infection and disease caused by S. japonicum have been reduced in China and Philippines, further reductions may be difficult because of the continual transmission from infected animals.

Normally, humans become infected with Schistosoma japonicum when cercarial forms of the parasite-released by freshwater snails-penetrate the skin during contact with infested water. When active or acute infections coincide with pregnancy, the conditions also exist for the possible transplacental passage of the parasite (schistosomulae) to the developing fetus. This mode of schistosome transmission is known as vertical transmission that leads to congenital infection of the fetus and has been reported by many researchers in a wide range of animals such as mice, rabbits, guinea pigs, dogs, goats, water buffaloes and cattle [1]-[6].

Immune relations between mothers and children have been demonstrated or detected in many diseases found in human. Many studies on different human parasitic diseases hypothesized that infection status of the mother may determine whether or not individuals who later become infected develop severe disease. A child born of a microfilaremic mother is 2.9 times more likely to become microfilaremic than a child born to an amicrofilaremic mother [7]. The same pattern is found in malaria-endemic areas where non-endemic individuals react differently from indigenous people [8].

Studies of animal models infected with schistosome showed that their offspring have altered immunity to subsequent infection [9]. Epidemiological evidences, combined with animal experiments, indicate that the pattern of disease and pathology in human schistosomiasis relates to previous exposure and immunologic experience to the parasite. Thus, most children born in areas endemic for schistosomiasis may be born of infected mothers. Individuals who move from non-endemic to endemic areas often experience more severe acute disease and subsequent pathology than indigenous populations [10] [11].

Intensity and duration of the infection are major determinants, but other factors are also involved. These include genetic background of the host, nutritional status, parasite strain differences, and frequency of infection. Maternal infection status has been proposed by many authors in order to explain the individual differences [12] [13].

The aim of the present study was to assess the effect of a congenital S. japonicum infection on the resistance of rabbit kittens to a postnatal challenge infection. We assessed several immunological parameters in kittens born of Schistosoma-infected mothers in comparison to those born of non-infected ones.

\section{Materials and Methods}

\subsection{Experimental Animals}

The experimental hosts were New Zealand white rabbits aged 16 - 17 weeks at the beginning of this experiment. The animals were allocated into three groups:

Group A $(n=4)$ : animals in this group had $\operatorname{IgM}^{+}$antibody titers and their kittens represent the congenital + challenge group.

Group B $(n=2)$ : Animals in this group had no serological evidence for infection with S. japonicum, their kittens represent the exposed + challenge group.

Group C $(n=3)$ : their kittens represent the challenge control group.

\subsection{Challenge Infection}

18 - 20 weeks after infection of their mothers, kittens were challenged percutaneously with a single dose of 100 S. japonicum cercariae (Chinese strain) through a shaved portion of the abdominal skin using the coverslip method described by [6] [14]. Rabbits will subsequently bred and maintained in isolators at the University of Huazhong animal facility, allowed free access of water and fed commercial rabbit chow.

\subsection{Antigens}

Soluble egg antigen (SEA) and adult worm antigen (AWA) Schistosoma japonicum were kindly provided by Head Department of Pathogenic Biology, Huazhong University, China. Antigen to be used in ELISA was a mixture of $20 \mu \mathrm{l}$ of SEA (at 1:500 dilution) and $300 \mu \mathrm{l}$ of AWA (at 1:1500 dilution) and $30 \mathrm{ml}$ of carbonatebicarbonate buffer (Ph 9.6). 


\subsection{Worm Recovery}

Adult worm were enumerated by hepatic perfusion of rabbits 6 weeks after challenge infection. The parasites harvested from each animal were counted.

\subsection{Tissue Egg Counts (EPG)}

At the time of perfusion, in all rabbits, one piece of liver (about $5 \mathrm{~g}$ ) was sampled. The frozen sample of the liver was minced and digested in $5 \% \mathrm{KOH}$ at $4^{\circ} \mathrm{C}$ for 12 - 18 hours. Egg counts of three $1 \mathrm{ml}$ portion of the suspension were determined by microscopic examination at $40 \times$. The mean of these counts was then used to be the EPG liver.

\subsection{Liver Granuloma Measurement}

Granuloma diameters were measures in histological sections. After portal perfusion, paraffin sections were routinely stained with HE for microscopic examination. In each histological section, 10 granulomas with visible central eggs were randomly selected; their diameters were measured at $10 \times$ magnification using calibrated ocular micrometer. The mean granuloma sizes for each rabbit in a group were averaged for statistical comparison.

\subsection{ELISA}

Schistosome-specific ELISA was performed using the following materials:

- $100 \mu \mathrm{l} /$ well of the antigen,

- $100 \mu \mathrm{l} /$ well of 1:100 rabbit's sera that obtained by cardiac puncture at the time of perfusion,

- $100 \mu \mathrm{l} /$ well of 1:3000 anti-IgM-HRP or 1:500 of anti-IgG—HRP and the substrate (OPD). $\mathrm{OD}_{492}$ values were read using an ELISA reader.

\subsection{Analysis of Data}

The Student's $t$-test was used to calculate the significance of the differences and a value of $P<0.05$ was taken as significant.

\section{Results}

\subsection{Worm Recovery}

Infection of rabbits with $S$. japonicum cercariae (100 cercariae/rabbit) resulted in a worm recovery of $60.66 \pm$ 5.85 worm/rabbit. The mean worm burden in Group A animals was $27.50 \pm 5.00$ worm/rabbit, producing a $54.66 \%$ reduction in challenge parasites $(P<0.001)$. In Group B animals, the recovery of challenge worms was $43.00 \pm 4.24$ worm/rabbit resulted in a percentage reduction of $29.11 \%(P<0.05)$, Table 1 .

\subsection{Liver Egg Counts}

The mean number of eggs deposited in the liver in the challenge control rabbit was found to be $800.66 \pm 19.00$ EPG. It was $486.75 \pm 42.69$ in Group A, showing a highly significant decrease of $41.45 \%$ in the total liver eggs $(P<0.001)$. Group B showed a $25.37 \%$ decrease in the total egg load compared with that in the challenge control rabbit $(P<0.01)$, Table 2 .

\subsection{Granuloma Size}

The mean size of granulomas in Group A animals was $49.30 \pm 6.68 \mu \mathrm{m}$, not compared with $102.2 \pm 17.14 \mu \mathrm{m}$ in the challenge controls $(P<0.01)$ whereas in Group B was $63.90 \pm 4.10 \mu \mathrm{m}$ resulted in a $37.48 \%$ reduction in granuloma size $(P<0.05)$, Table 3 .

\subsection{Immunological Findings}

6 weeks after challenge infection, the mean IgM response to schistosome antigen in Group A was found to be $0.8293 \pm 0.21(P<0.001)$ whereas in Group B was $0.9285 \pm 0.016(P<0.05)$. Comparing with Group C ani- 
mals which exhibited the highest absorbance (1.3660 \pm 0.13$)$, Table 4.

\subsection{IgG Responses}

Group B-kittens showed a $18.75 \%$ increases in the specific IgG antibody response $(P<0.05)$. Group A-kittens displayed further increase in this response $(56.22 \%$ increment; $P<0.001)$, Table 5.

\section{Discussion}

Rabbits with an S. japonicum congenital infection 16 weeks previously showed a $54.66 \%$ resistant against the challenge infection. This is in keeping with the previous conclusion that the challenge infection of pigs did not result in higher worm burden and higher tissue egg counts compared to the primary control group or the challenge control group [15]. Adult worm count was significantly reduced in the offspring of Schistosoma-infected

Table 1. Adult worm recoveries (worm burdens) and reduction rates (\% protection) after challenge infection.

\begin{tabular}{ccccc}
\hline Group & Infection status & Worm burden & Protection & $P$-value \\
\hline A & Congenital + challenge & $27.50 \pm 5.00$ & 54.66 & $<0.001$ \\
B & Exposed + challenge & $43.00 \pm 4.24$ & 29.11 & $<0.05$ \\
C & Challenge control & $60.66 \pm 5.85$ & & \\
\hline
\end{tabular}

Table 2. Geometric mean number of tissue egg counts and the percentage reduction in challenge egg deposition in the liver.

\begin{tabular}{ccccc}
\hline Group & Infection status & Mean EPG & Reduction & $P$-value \\
\hline A & Congenital + challenge & $468.75 \pm 42.69$ & 41.45 & $<0.001$ \\
B & Exposed + challenge & $597.50 \pm 38.89$ & 25.37 & $<0.01$ \\
C & Challenge control & $800.66 \pm 19.00$ & & \\
\hline
\end{tabular}

Table 3. Granuloma sizes in different groups of rabbits 6 weeks after a single dose of 100 cercariae/rabbit.

\begin{tabular}{ccccc}
\hline Group & Infection status & Granuloma size $(\mu \mathrm{m})$ & Reduction & $P$-value \\
\hline A & Congenital + challenge & $49.30 \pm 6.68$ & 51.76 & $<0.01$ \\
B & Exposed + challenge & $63.90 \pm 4.10$ & 37.48 & $<0.05$ \\
C & Challenge control & $102.2 \pm 17.14$ & & \\
\hline
\end{tabular}

Table 4. Mean $\mathrm{OD}_{492 \mathrm{~nm}}$ values for IgM responses to (SEA + AWA).

\begin{tabular}{ccccc}
\hline Group & Infection status & Mean $\mathrm{OD}_{492 \mathrm{~nm}}$ & Reduction (\%) & $P$-value \\
\hline $\mathrm{A}$ & Congenital + challenge & $0.8293 \pm 0.21$ & 39.47 & $<0.01$ \\
$\mathrm{~B}$ & Exposed + challenge & $0.9285 \pm 0.016$ & 32.03 & $<0.05$ \\
$\mathrm{C}$ & Challenge control & $1.3660 \pm 0.13$ & & \\
\hline
\end{tabular}

Table 5. Mean $\mathrm{OD}_{492 n m}$ values for IgG responses to (SEA + AWA) preparation in the different groups of rabbits.

\begin{tabular}{cccc}
\hline Group & Infection status & Mean OD $492 \mathrm{~nm}$ & Increment rate (\%) \\
\hline A & Congenital + challenge & $0.9748 \pm 0.07$ & 56.22 \\
B & Exposed + challenge & $0.741 \pm 0.006$ & 18.75 \\
C & Challenge control & $0.624 \pm 0.03$ & \\
\hline
\end{tabular}


mothers compared to mice born to non-infected ones, but no explanation was offered [16]. One possible reason for the presence or absence of severe pathology is prenatal exposure to schistosomiasis that modulates the future immune response later in life [17]. This notion has been suggested by many authors and has been explored in experimental models [18]-[20]. This could be explained by the concept of development of concomitant immunity [21] in which continuous antigenic stimulation (by the presence of some adult worms) stimulates protective immune response against further infections. Early stimulation of the immune system by in utero exposure to schistosomiasis may, therefore, provide quite strong protective immunity against initial postnatal infections. In sum, congenital exposure to Schistosoma infection seems to reduce the intensity of infection in subsequent postnatal exposure.

The congenitally-infected group also had a lower proportion of tissue eggs suggests that the previous infection status are able to destroy liver deposited eggs fairly rapidly. As considered by earlier this could be due to the host's immunological response interfering with the uptake of essential nutrients by the parasite [22].

The present results show that the challenge infection reduces the magnitude of granulomatous responses of a postnatal challenge infection. The same observation had been made by many researchers [16] [19] [23]-[25]. The reduced size of granulomas observed by many authors and in our experiment in congenitally exposed kittens may be attributed to attenuated Th2 response. The latter may be due to, at least in part, an increase in counter-regulatory cytokines such as IL-12 and TGF- $\beta$ or could be explained by an induction of immunological tolerance [26]-[28].

The present study shows that the congenital infection increases the IgM and IgG antibody titers compared to the exposed kittens. Modification of the immune response to schistosomal antigens, which may constitute the basis for these differences in this experiment, has been demonstrated in children born to S. mansoni-infected mothers. It has been found that Schistosoma-specific IgG levels were lower in prenatally exposed mice compared to control [16]. This in contrast to the finding that a highly significant increase in total IgG in offspring born to $S$. mansoni-infected mothers compared to offspring born to non-infected ones [28]. Because it was not clear what kind of antibody and how antibody is needed for protection, immunological analysis of its protection by the congenital infection would be necessary for future study.

To our knowledge, this is the first report to investigate the S. japonicum/rabbit model showing the effect of congenital infection on these variables. The findings from the present study might have wide implications for the regulatory response to infection and the associated clinical and pathological consequences of S. japonicum infection and it may assist in further exploration of mechanisms and elucidation of causative role of $S$. japonicum infection in the mammalian host.

These results can be relevant to humans since many children are indeed born to infected mothers in endemic areas who are rarely manifest acute manifestations such as acute dermatitis or katayama fever [29]. This will add to the complexity of the situation, and might provide a stronger background for immunomodulation in subsequent infections.

\section{Conclusion}

In conclusion, congenital exposure to $S$. japonicum infection affects the immune response and the disease outcome in the future postnatal infections; the intensity of the infection as well as the immune-pathological changes is moderated in congenitally exposed kittens. Finally, these results may give us insight for prevention and control strategies in schistosomiasis and perhaps in other chronic infectious diseases as well.

\section{References}

[1] Narabayashi, H. (1916) Contribution to the Study of Schistosomiasis Japonicum. Kyoto Igako Zasshi, 13, 231-278. (in Japanese)

[2] Kikuchi, S. (1957) Studies on Placental Infection of Schistosoma japonicum. Sogo Igaku, 14, 537-544.

[3] Wang, X.Y. (1958) Transplacental Infection of Schistosomiasis Japonica in Cattle. Research References of Schistosomiasis Japonica. The Shanghai Institute of Parasitic Diseases, Shanghai Science and Technology Press, 731-732. (in Chinese)

[4] Okabe, K. (1961) Biology and Epidemiology of Schistosomiasis Japonica. In: Morishita, K., Komiya, Y. and Matsubayashi, H., Eds., Progress of Medical Parasitology in Japan, Megguro Parasitology Museum, Tokyo, 55-80.

[5] Willingham, A.L., Johansen, M.V., Bǿgh, H.O., Eto, A., Andreassen, J., Lindberg, R., Christensen, N.Q. and Nansen, 
P. (1999) Congenital Transmission of Schistosoma japonicum in Pigs. American Journal of Tropical Medicine and Hygiene, 60, 311-312.

[6] Qian, B.-Z., Bǿgh, H.O., Johansen, M.V. and Wang, P.P. (2000) Congenital Transmission of Schistosoma japonicum in the Rabbit. Journal of Helminthology, 74, 267-270.

[7] Hightower, A.W., Lammie, P.J. and Eberhard, M.L. (1993) Maternal Filarial Infection-A Persistent Risk Factor for Microfilaraemia in offspring? Parasitology Today, 9, 418-421. http://dx.doi.org/10.1016/0169-4758(93)90051-G

[8] Rasheed, F.N., Bulmer, J.N., De Francisco, A., Jawla, M.F.B., Jakobsen, P.H., Jepson, A. and Greenwood, B.M. (1995) Relationships between Maternal Malaria and Malarial Immune Responses in Mothers and Neonates. Parasite Immunology, 17, 1-10. http://dx.doi.org/10.1111/j.1365-3024.1995.tb00960.x

[9] Harn, D.A., Mitsuyama, M. and David, J.R. (1984) Schistosoma mansoni: Anti-Egg Monoclonal Antibodies Protect against Cercarial Challenge in Vivo. Journal of Experimental Medicine, 159, 1371-1387. http://dx.doi.org/10.1084/jem.159.5.1371

[10] Morieatry, P.L. and Lewert, R.M. (1985) Delayed Hypersensitivity in Ugandan Schistosomiasis. II. Epemiological Patterns of Intradermal Responses. American Journal of Tropical Medicine and Hygiene, 23, 179-189.

[11] Nash, T.E., Cheever, A.W., Ottesen, E.A. and Cook, J.A. (1982) Schistosome Infections in Humans: Perspectives and Recent Findings. Annals of Internal Medicine, 97, 740-754. http://dx.doi.org/10.7326/0003-4819-97-5-740

[12] Butterworth, A.E. and Thomas, J.E.P. (1999) Schistosomiasis. In: Weatherall, D.J., Ledingham, T.G.G. and Warell, D.A., Eds., Oxford Textbook of Medicine, Vol. 1, 3rd Edition, Oxford University Press Inc., New York, 970-981.

[13] Pearce, E.J. and Andrew, S.M. (2002) The Immunology of Schistosomiasis. Nature Reviews Immunology, 2, $499-511$.

[14] Peters, P.A. and Warren, K.S. (1969) A Rapid Method of Infecting Mice and Other Laboratory Animals with Schistosoma mansoni: Subcutaneous Injection. The Journal of Parasitology, 55, 558. http://dx.doi.org/10.2307/3277297

[15] Willingham, A.L., Johansen, M.V., Bǿgh, H.O., Qian, B.-Z. and Wang, P.P. (1997) Schistosoma japonicum in the Pig: the Effect of a Patent Primary Infection on a Challenge Infection. Acta Tropica, 66, 51-59. http://dx.doi.org/10.1016/S0001-706X(97)00662-1

[16] Attallah, A.M., Abbas, A.T., Dessouky, M.I., El-emshaty, H.M. and Elsheikha, H.M. (2006) Susceptibility of Neonate mice Born to Schistosoma mansoni-Infected and Non-Infected Mothers to Subsequent S. mansoni Infection. Parasitology Research, 99, 137-145. http://dx.doi.org/10.1007/s00436-006-0127-x

[17] Malhotra, I. Ouma, J. Wamachi, A., Kioko, J. Mungai, P. Omollo, A., Elson, L. Koech, D., Kazura, J.W. and King, C.L. (1997) In Utero Exposure to Helminthes and Mycobacterial Antigens Generates Cytokine Responses Similar to That Observed in Adults. The Journal of Clinical Investigation, 99, 1759-1766. http://dx.doi.org/10.1172/JCI119340

[18] Camus, D., Carlier, Y., Bina, J.C., Borojevic, R., Prata, A. and Capron, A. (1976) Sensitization to Schistosoma mansoni Antigen in Uninfected Children Born to Infected Mothers. The Journal of Infectious Diseases, 134, 405-408. http://dx.doi.org/10.1093/infdis/134.4.405

[19] Montesano, M.A., Colley, D.G., Eloi-Santos, S., Freenan, G.L. and Secor, W.E. (1999) Neonatal Idiotypic Exposure Alters Subsequent Cytokine, Pathology, and Survival Patterns in Experimental Schistosoma mansoni Infections. The Journal of Experimental Medicine, 189, 637-645. http://dx.doi.org/10.1084/jem.189.4.637

[20] King, C.L. (2001) Initiation and Regulation of Disease in Schistosomiasis. In: Mahmoud, A.F., Ed., Schistosomiasis (Tropical Medicine: Science and Practice), Imperial College Press, London, 213-256. http://dx.doi.org/10.1142/9781848161511_0006

[21] Hagan, P. (1996) Immunity and Morbidity Due to Schistosoma haematobium. American Journal of Tropical Medicine and Hygiene, 55, 116-120.

[22] Domian, R.T., Greene, N.D. and Meyer, K.F. (1976) Schistosoma mansoni in Baboons. III. The Course and Characteristics of Infection with Additional Observations on Immunity. American Journal of Tropical Medicine and Hygiene, 25, 299-306.

[23] Lewert, R.M. and Mandlowitz, S. (1969) Schistosomiasis: Prenatal Induction of Tolerance to Antigens. Nature, 224, 1029-1030. http://dx.doi.org/10.1038/2241029a0

[24] Hang, L.M., Boros, D.L. and Warren, K.S. (1974) Induction of Immunological Hyporesponsiveness to Granulomatous Hypersensitivity in Schistosoma mansoni Infection. The Journal of Infectious Diseases, 130, 515-522. http://dx.doi.org/10.1093/infdis/130.5.515

[25] Stavitsky, A.B. (2004) Regulation of Granulomatous Inflammation in Experimental Models of Schistosomiasis. Infection and Immunity, 72, 1-12. http://dx.doi.org/10.1128/IAI.72.1.1-12.2004

[26] Alves-Oliveira, L.F., Moreno, E.C., Gazzinelli, G., Martins-Filho, A.O., Silveira, A.M.S., Gazzinelli, A., Malaquias, L.C.C., LoVerde, P., Martins Leite, P. and Correa-Oliveira, R. (2006) Cytokine Production Associated with Periportal 
Fibrosis during Chronic Schistosomiasis mansoni in Humans. Infection and Immunity, 74, 1215-1221. http://dx.doi.org/10.1128/IAI.74.2.1215-1221.2006

[27] Chu, D., Luo, Q., Li, C., Gao, Y. Yu, L., Wei, W., Wu, Q. and Shen, J. (2007) Paeoniflorin Inhibits TGF-Beta1-Mediated Collagen Production by Schistosoma japonicum Soluble Egg Antigen in Vitro. Parasitology, 134, 1611-1621. http://dx.doi.org/10.1017/S0031182007002946

[28] Ahmad, A.O., Zeinab, S.S., Eman, M.S. and Rasha, H.S. (2010) Congenital Exposure to Schistosoma mansoni Infection: Impact on the Future Immune Response and the Disease Outcome. Immunobiology, 215, 101-112. http://dx.doi.org/10.1016/j.imbio.2009.04.004

[29] Caldas, I.R., Campi-Azevedo, A.C., Alves-Oliveira, L.F., Silveira, A.M.S., Oliveira, R.C. and Gazzinelli, G. (2008) Human Schistosomiasis mansoni: Immune Responses during Acute and Chronic Phases of the Infection. Acta Tropica, 108, 109-117. http://dx.doi.org/10.1016/j.actatropica.2008.05.027 
Scientific Research Publishing (SCIRP) is one of the largest Open Access journal publishers. It is currently publishing more than 200 open access, online, peer-reviewed journals covering a wide range of academic disciplines. SCIRP serves the worldwide academic communities and contributes to the progress and application of science with its publication.

Other selected journals from SCIRP are listed as below. Submit your manuscript to us via either submit@scirp.org or Online Submission Portal.
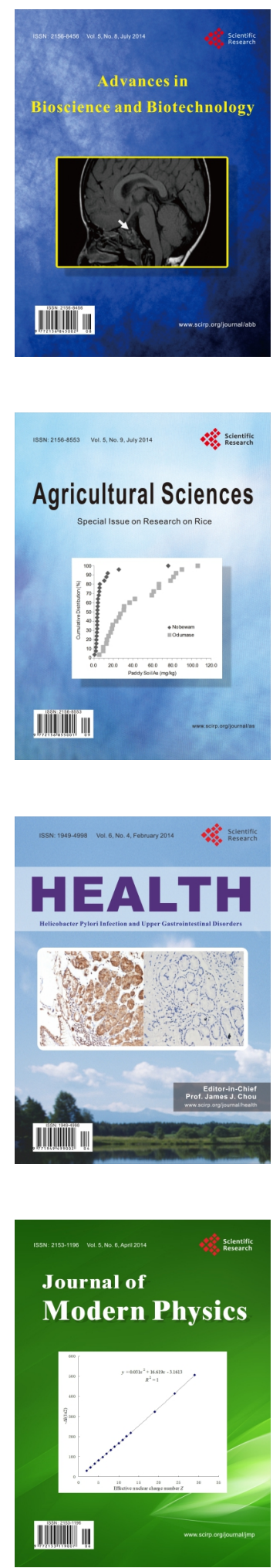
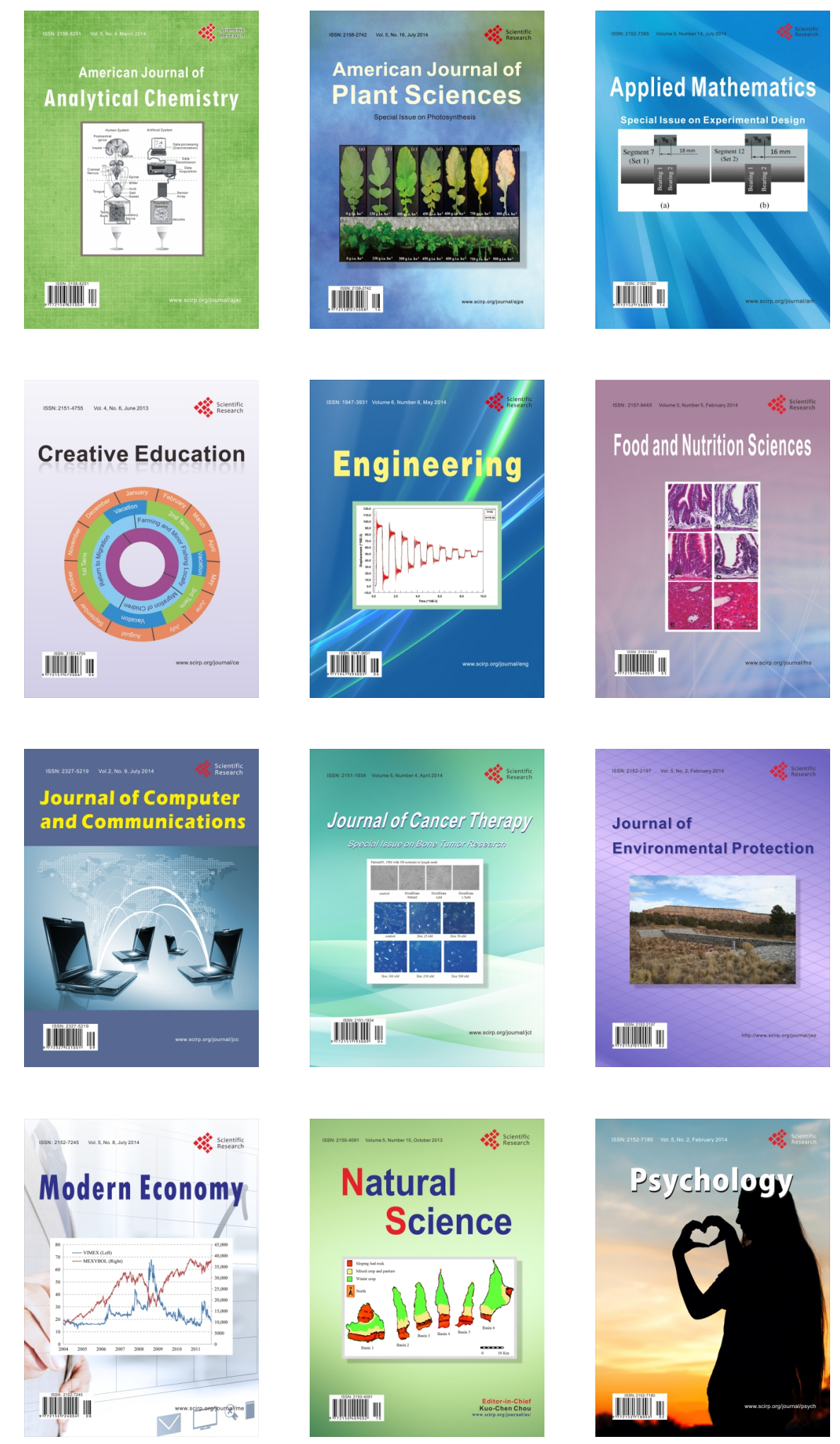